\title{
Emergency care in India: the building blocks
}

\author{
Imron Subhan • Anunaya Jain
}

Received: 25 February 2010 /Accepted: 11 July 2010 /Published online: 4 August 2010

(C) The Author(s) 2010. This article is published with open access at Springerlink.com

\begin{abstract}
Background The Republic of India, the world's most populous democracy, has struggled with establishing Emergency Medical Care. However, with the recent recognition of Emergency Medicine as a formal specialty in medical training, there has been renewed vigor in the developments in the field.

Method and Results We outline here the building blocks of the health care system in India, and the contribution each has made and is capable of making to the growth of emergency medical services. We also provide an account of the current situation of emergency medicine education in the country.

Conclusions As we trace the development and status of emergency medicine in India, we offer insight into the current state of the field, what the future holds for the emergency medical community, and how we can get there.
\end{abstract}

Keywords Emergency medicine .

Emergency medical services - Medical education .

International $\cdot$ India $\cdot$ Development $\cdot$ Current status

The views expressed in this paper are those of the author(s) and not those of the editors, editorial board or publisher.

I. Subhan

Department of Emergency Medicine, Apollo Health City, Jubillee Hills,

Hyderabad, Andhra Pradesh, India, 500033

e-mail: imronsubhan@gmail.com

A. Jain $(\bowtie)$

Department of Emergency Medicine, University of Rochester, 601 Elmwood Ave, 655A, Rochester, NY 14620, USA

e-mail: anunaya_jain@urmc.rochester.edu

\section{Introduction}

The Republic of India is the seventh largest country in the world and is home to nearly 1.2 billion people. With 28 states and 7 union territories (Fig. 1) spread over a vast geographic area with varying economic resources and infrastructure, India is the world's most populous democracy.

The India of today is a young nation, finding its roots in socioeconomic development, and is plagued by challenges in health care created by its overwhelming population density of $943.9 / \mathrm{mile}^{2}$, its limited ability to expand health care, the persistent burden of communicable diseases, and the rising liability of diseases of affluence [1,2].

\section{Health care provision}

Health care provision in India is multi-pronged, including a tiered national health system, private hospitals, and a multitude of alternative medicine practitioners.

The National Health Policy (NHP) was first formulated in 1983 [3]. This policy-guided government effort aims to provide health for all by outlining a time-bound phased setup of comprehensive primary health care services throughout the country. Under its aegis, health care services in centralized hospitals were made free for people below the poverty line, and numerous preventive programs were initiatied. The first review of the NHP in 2002 focused on the new objective of achieving an acceptable standard of good health among the general population of the country by advocating higher expenditure on health care with equitable access to health care services [4].

The tiered system of public health care is highlighted in Fig. 2. It serves as the front line of emergency medical care for the masses. The system has remained plagued by a lack of accountability and staffing. According to the $2004 \mathrm{WHO}$ statistics, the number of PHCs in India is 23,109 , which is 
Fig. 1 Political map of India

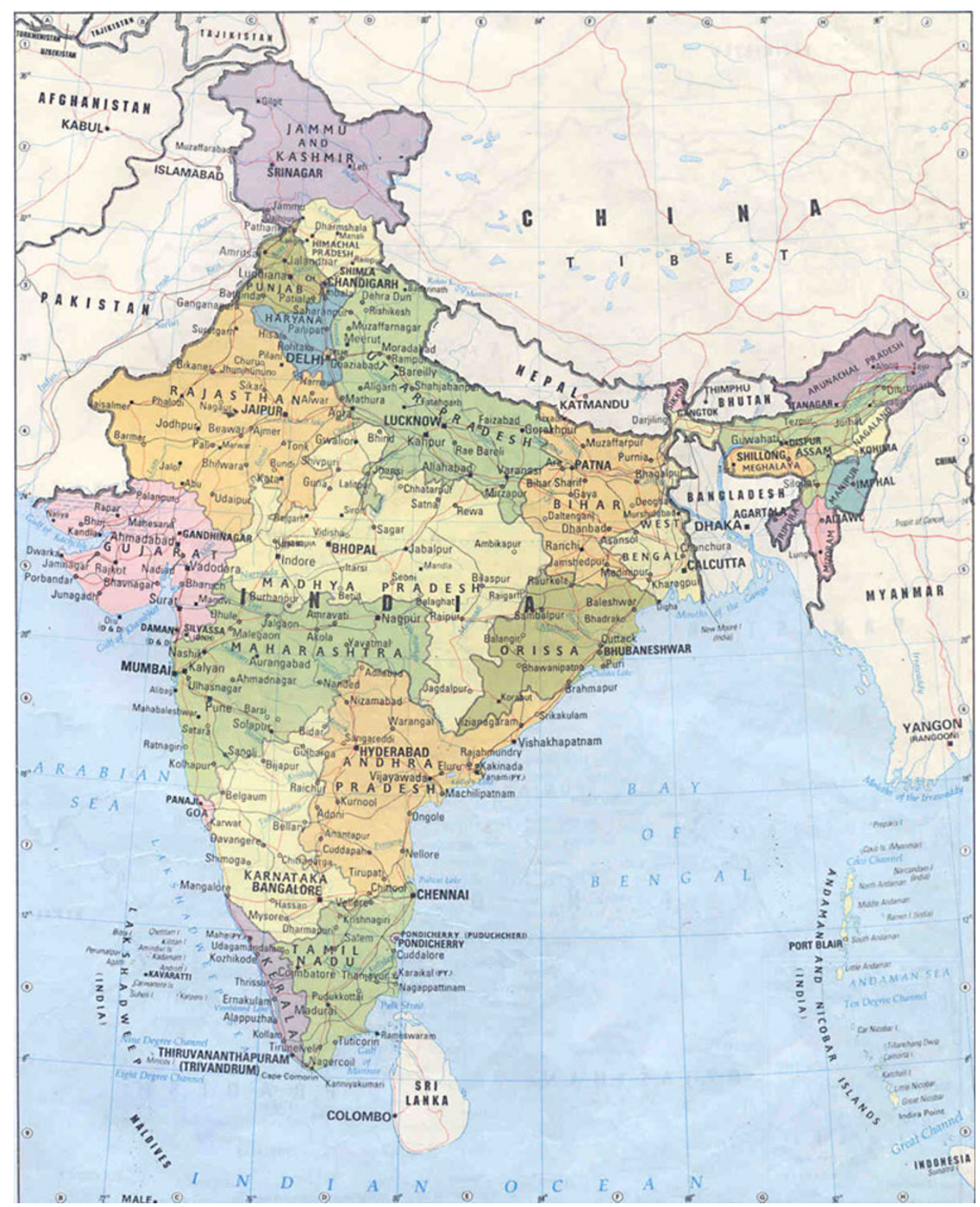

far below the required number. The lack of organized prehospital care coupled with the lack of resources and the high volume of patients that throng the government-run tertiary care hospitals further compound problems [7].

This system is further complicated by the unregulated expansion of private health care facilities in the country. The average person today considers expenditure in these private hospitals to receive health care far more acceptable than submitting to the unprofessionalism rampant in many of the public health care delivery areas. This has prompted an anarchy of sorts, with the private hospitals dictating costs.

The lack of universal medical insurance only compounds this issue, as do the limited economic resources. The federal expenditure on health care in India was $8.8 \%$ of the GDP in 2003. The public expenditure was only $25 \%$, whereas the private expenditure was $75 \%$, a practice very different from developed nations like the USA [5]. The WHO also estimated that the share of social insurance in India was only about $4.2 \%[6]$.

\section{Emergency care in India}

Although emergency physicians and emergency medicine have remained a realized need in the country, the practice of emergent care has remained centralized, with traditionally few private hospitals admitting emergency cases [11] as they prefer to avoid dealing with medico-legal formalities during emergencies (Supreme Court of India; Parmanand Katara vs. Union of India AIR1989SC 2039) [8]. This 
Fig. 2 Tiered health care system

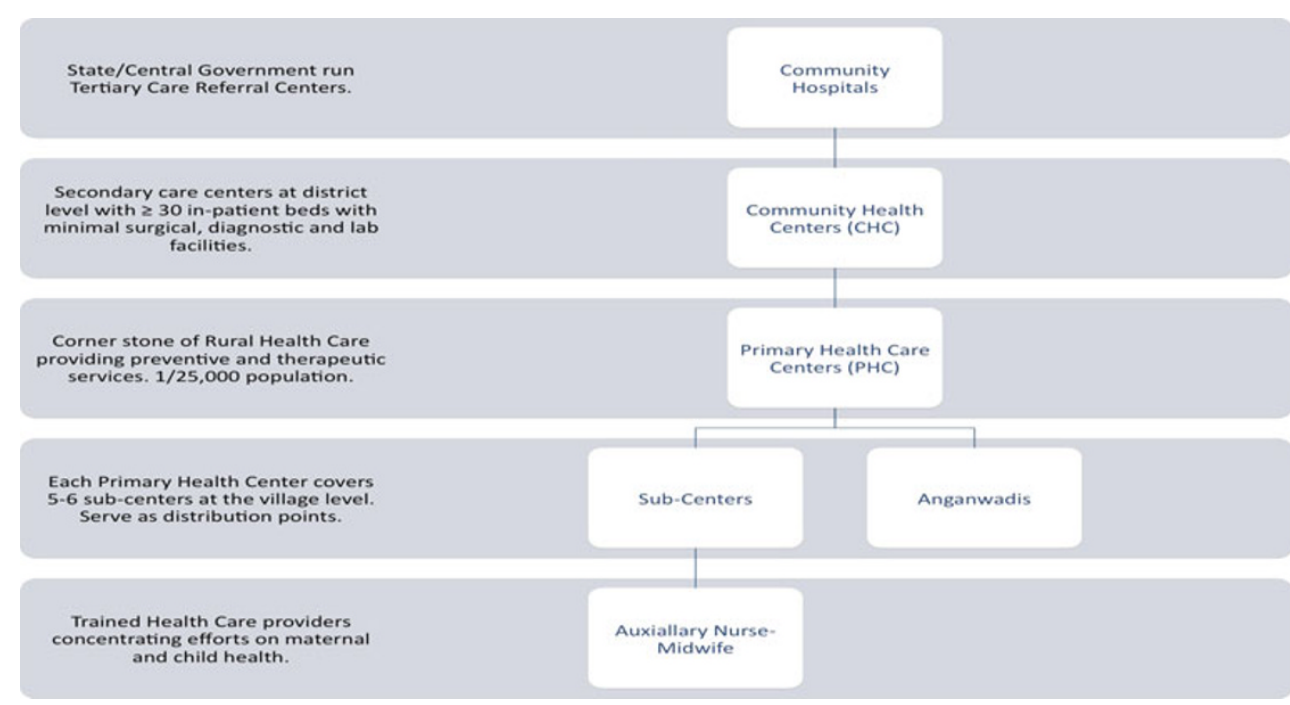

problem was mitigated to some extent when the judicial system mandated the delivery of care by any and every hospital regardless of a patient's paying and medico-legal status in times of emergency [9]. Failure on the part of any hospital to provide timely medical treatment to a person in need of such treatment results in a violation of the patient's "Right to Life," which is guaranteed under Article 21 of the Constitution of India [10]. This is the closest India has come to enacting laws similar to The EMTALA (Emergency Medical Treatment and Labor Act) and the COBRA (Consolidated Omnibus Budget Reconciliation Act), which are well recognized in the USA.

Most emergency departments in centrally run university and government hospitals do not match up to the "Emergency Department Categorization Standards" proposed by the Society of Academic Emergency Medicine (SAEM) [14]. Emergency care is offered in areas designated as 'casualties' that are often manned by junior specialty residents with little overview and are mere 'referral points' for specialized care. Triage, something that is instrumental to good emergency care, is rarely practiced. Problems are worse in rural areas, where even the most basic emergency obstetric care has been found to be lacking [12].

On a completely different level, however, is the defense sector in India, in which command hospitals, paramedics, and nurses trained in emergency medicine have long been functioning.

The first privatized emergency department (ED), modeled on the American Community Hospital Emergency system, was established at the Sundaram Medical Foundation, Chennai, with help and support from emergency physicians from the Long Island Jewish Medical Center, USA, in the late 1990s [13]. This marked a landmark change in the psyche of the private hospitals in the country. Today, wellequipped EDs have cropped up in private medical centers all over the country, and many of these centers are headed by physicians who have formally trained in emergency medicine in other countries.

\section{EMS in India}

The EMS system in India is best described as 'fragmented.' The basic fundamental principal behind EMS systems worldwide is to have a common emergency communication number connected to responsive agencies. Although India has the emergency number 102 for calling ambulances, the responsiveness of the system has always been doubted. In 2007 , Ramanujam et al. reported that nearly $50 \%$ of trauma victims admitted to a premier hospital in an urban Indian city had received no pre-hospital care [15].

The first of its kind, the CATS (Centralized Accident and Trauma Services) ambulance system was conceptualized in 1984 [16]. The service was expanded nationally, but lack of a driving force behind the initiative made it fall by the side. Today, NGOs (non-governmental organizations) and private hospitals in cities and states have constructed their own EMS setups. Principal among these are the National Network of Emergency Services (NNES), Ahmedabad, Delhi, Pune, Hyderabad, Chennai, Raipur, Ranchi, and Kolkata [17]; Emergency Management and Research Institute (EMRI), Haryana, Chandigarh, Uttaranchal, Rajasthan, Gujarat, Madhya Pradesh, Andhra Pradesh, Goa, Karnataka, Tamil Nadu, Meghalaya, and Assam [18]; Life Support Ambulance Service (LSAS), Kerala, Mumbai [19]; Operation Sanjeevani, Bengaluru; Ambulance Access for All (AAA), Mumbai; Indian Institute of Emergency Medical Services (IIEMS), Kerela, etc.

Lack of a uniform EMS access number across the country and the lack of awareness among commuters about the existing numbers makes access and egress from emergencies difficult [20]. The lack of trained professio- 
nals manning ambulances makes quality of care heterogeneous. EMS services have remained unaccountable, and this has led to failure to introduce corrective measures for improving EMS in India.

However, steps are being taken in the right direction. The Gujarat state government set up the Gujarat Emergency Medical Services Authority (GEMSA). This was the first state to actually pass an Emergency Services Regulation in the country. By bringing together government, NGOs and other private agencies, a statewide system of emergency care has been set up, which could signal a tide of vital change in EMS.

Collaborations with internationally acclaimed institutes like Stanford University, CA (EMRI) and the American Association of Physicians of Indian Origin (AAPI) have provided several breakthroughs in technical and educational expertise.

There is palpable vigor among the bureaucratic brass and political leadership regarding re-initiating the process for allotting a unique emergency response number. How successful this push will be remains to be seen!

\section{Emergency medicine education}

One of the shining beacons in Indian emergency medicine has been the evolution of academic training for physicians. Medical colleges have always emphasized a minimum of 2 weeks spent in 'casualties' of hospitals during the mandatory year of internship training prior to obtaining the baccalaureate in medicine and surgery.

The lack of specialist training in the field was one of the principal issues highlighted by the white paper on Indian emergency medicine published by the INDUS collaboration [21]. David et al., in their landmark article, suggested that one of the three important prongs essential for the development of emergency medicine in India was the development of formal education in emergency medicine with its recognition as a specialty by the Medical Council of India [22].

Since then, several institutes have instituted formal training in emergency medicine. Most of these have been developed in collaboration with international agencies, including RCGP UK (Royal College of General Practitioners, UK), CEM UK (College of Emergency Medicine, UK), GWU USA (George Washington University, USA), etc. Others have formulated locally modulated curricula for training in emergency medicine.

The recognition of Emergency Medicine as the 30th specialty in medical training by the medical council of India in July 2009 brought about a welcome change. There is now a move to increase the number of eligible seats for training in emergency medicine throughout the country. The FACET program started by the INDUS collaboration in 2009 is a future faculty development program that will give rise to local champions for emergency medicine education [23].
There has also been a surge in training programs for emergency medicine nursing and paramedic training. Spearheading this effort are the WHO-recognized Emergency Nursing course at CMC Vellore and the collaboration with Stanford University at EMRI. Several other private institutes and hospitals have also initiated diploma courses towards the same goal. The EMRI Emergency Nurses Award (EENA), initiated in 2005 to recognize nurses' excellence in Emergency Medicine, is a step towards recognition of these important pieces of the puzzle [24]. However, the absence of a regulatory body puts the uniformity of training into question.

There has also been a move towards making emergency medicine a trainable specialty under the National Board of Examination (NBE) training programs run at private and public sector hospitals within the country. The parallel introduction of simulation facilities and a variety of training programs in emergency ultrasound and resuscitation throughout the country will further interest in the field among young physicians [25].

\section{Emergency medicine interest groups}

Several interest groups have been instrumental in the development of emergency medicine. SEMI, the Society of Emergency Medicine in India, was started in 1999 [26] and has served as an important forum not only for national emergency physicians to brainstorm the steps for the development of emergency medicine in the country, but they have also served as an important focal point of contact with other international agencies like the ACEP (American College of Emergency Physicians). AAEMI, the American Academy for Emergency Medicine in India, was established in 2001 and has partnered with SEMI in order to bring attention and recognition to Indian Emergency Medicine [27]. The more recent Indo-US Emergency and Trauma Collaborative (INDUS) has furthered the cause of nationalized emergency medicine education in India [28]. NEPI, the Network of Emergency Physicians in India, is a virtual network of emergency physicians and aspirants in the field that provides a venue to engage in academic, administrative, and research-related discussions about emergency medicine in India [29].

\section{The future}

A collaborative effort is needed not only by the medical community, but also by other agencies to reform the emergency response system in India. With India burdened by the most traffic accidents in the world, it is important to fight this problem with awareness drives among the general 
population. What is needed is a championed effort to bring everyone together towards the greater common good. Privatepublic partnership, which is lacking today, seems to be the most viable way to proceed if we want to develop a system that not only works, but also avoids the mistakes of the past.

As a country of over a billion people, our needs and resources differ from most other countries in the world. We cannot simply hope to copy the established systems, but we can surely hope to learn from them. By collaborating with agencies worldwide, we can bring in the essential technical expertise to truly reform the system.

Perhaps what is most essential to develop Indian Emergency Medicine is to stimulate the young minds of graduating physicians, nurses, and paramedics to see Emergency Medicine as a career opportunity and to influence decision makers to formulate policy conducive to fair practice and training in emergency medicine.

\section{Conflicts of Interest None.}

Open Access This article is distributed under the terms of the Creative Commons Attribution Noncommercial License which permits any noncommercial use, distribution, and reproduction in any medium, provided the original author(s) and source are credited.

\section{References}

1. Krishnaswami S, Joseph G, Richard J (1991) Demands on tertiary care for cardiovascular diseases in India: analysis of data for 1960-1989. Bull World Health Organ 69:325-330

2. Reddy KS (2007) India wakes up to the threat of cardiovascular diseases. J Am Coll Cardiol 50:1370-1372

3. Ministry of Health and Family Welfare ND, India. National Health Policy (1983) http://www.mohfw.nic.in/kk/95/ii/95ii0101.htm.

4. Ministry of Health and Family Welfare ND, India. NATIONAL HEALTH POLICY 2002 (India). 2002; http://www.mohfw.nic. in/NRHM/Documents/National_Health_policy_2002.pdf.

5. India: New Directions in Health Sector Development at the State Level (1997) The World Bank.

6. WHO. National Health System Profile : India (2007).

7. PoSaw LL, Aggarwal P, Bernstein SL (1998) Emergency medicine in the New Delhi area, India. Ann Emerg Med 32:609-615

8. Rao JJ (2006) The Law Commission of India. http://awcommis sionofindia.nic.in/reports/rep201.pdf.

9. Mathiharan K (2003) The fundamental right to health care. Issues Med Ethics 11:123

10. Constitution I. Article 21. http://rshrc.nic.in/07\%20Human $\%$ 20Right $\% 20$ Article-21.pdf.

11. Aggarwal P, Banga A, Kurukumbi M, Gupta M (2001) Emergency physicians and emergency medicine: an imminent need in India. Natl Med J India 14:257-259

12. Mavalankar DV (2002) Policy and management constraints on access to and use of life-saving emergency obstetric care in India. J Am Med Womens Assoc;57:165-6, 8
13. Alagappan K, Cherukuri K, Narang V, Kwiatkowski T, Rajagopalan A (1998) Early development of emergency medicine in Chennai (Madras), India. Ann Emerg Med 32:604-608

14. Goldfrank L, Henneman PL, Ling LJ, Prescott JE, Rosen C, Sama A (1999) Emergency center categorization standards. Acad Emerg Med 6:638-655

15. Ramanujam P, Aschkenasy M (2007) Identifying the need for prehospital and emergency care in the developing world: a case study in Chennai, India. J Assoc Physicians India 55:491-495

16. Government of Delhi I. Centralized Accident \& Trauma Services (CATS). http://health.delhigovt.nic.in/Cats/content.html.

17. Apollo Hospitals I. National Network of Emergency Services. http://www.apollohospitals.com/component/content/article/332. html.

18. GVK-EMRI. Emergency Medicine Research Institute. http://www. emri.in/.

19. 1298. Life Support Ambulance Service. http://www.1298.in/.

20. David SS (1997) Strategy for the development of emergency medical services in India. J Indian Med Assoc;95:17, 26.

21. Das AK, Gupta SB, Joshi SR et al (2008) White paper on academic emergency medicine in India: INDO-US Joint Working Group (JWG). J Assoc Physicians India 56:789-798

22. David SS, Vasnaik M (2007) T VR. Emergency medicine in India: why are we unable to 'walk the talk'? Emerg Med Australas 19:289-295

23. FACET-INDIA. http://www.facetindia.org/.

24. Jampala A (2006) Celebrating emergency nurses in India. J Emerg Nurs 32:122-123

25. Gupta A, Peckler B, Schoken D (2008) Introduction of hi-fidelity simulation techniques as an ideal teaching tool for upcoming emergency medicine and trauma residency programs in India. J Emerg Trauma Shock 1:15-18

26. SEMI - Society for Emergency Medicine in India. http://www. semi.org.in/index.php.

27. American Academy for Emergency Medicine in India. http:// www.aaemi.org/aaemi/aaemi_born.htm.

28. Indo-US Emergency and Trauma Collaborative. http://www. indusem.com/.

29. Network of Emergency Physicians India. http://nepi.emergency medicine.in/.

Dr. Imron Subhan, MBBS FEM, MCEM (UK) Dr. Imron Subhan has been an effective member of the small but extremely active emergency medicine community in India. After finishing his fellowship in Emergency Medicine at CMC Vellore, he pursued a formal residency in Emergency Medicine at Apollo Health City, Hyderabad, India, under the aegis of the College of Emergency Medicine, UK. Since finishing this program, Dr. Subhan has been a consultant at Apollo and has been guiding young emergency medicine residents as well as professionals at the national level. With his endearing presence at national conferences as a faculty member, and his interest in academics and administration, he has become an essential part of the EM puzzle in India. He is also one of the founding members of the Network of Emergency Physicians in India (NEPI) and www.emergencymedicine.in.

Dr. Anunaya Jain, MBBS, MCEM (UK) Dr. Anunaya Jain completed his residency in emergency medicine at Apollo Health City and since has been pursuing his research interests in the USA. He has worked as a research fellow at the Mayo Clinic and is currently at the University of Rochester, NY. His chief area of interest is neurological emergencies, and he has a never-ending commitment to the development of academic emergency medicine in India. He has been pivotal in guiding young physicians towards emergency medicine via his web forums. 